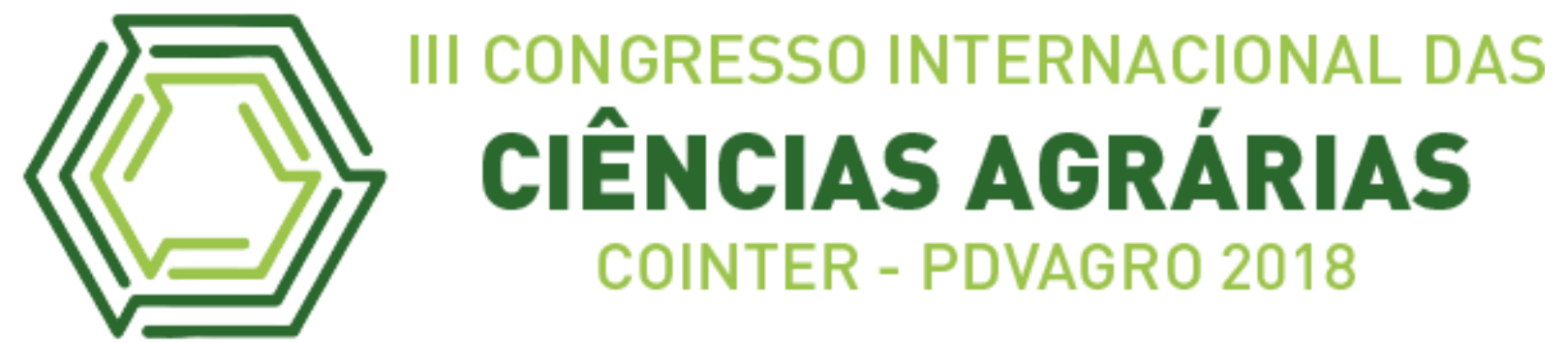

\title{
DEPOSIÇÃO DE CALDA APLICADA EM PLANTAS DE SOJA COM DIFERENTES VOLUMES
}

\section{DEPOSITION IN SOYBEAN PLANTS WITH DIFFERENT PULVERIZATION VOLUMES}

Apresentação: Pôster

\begin{abstract}
Roxana Stefane Mendes Nascimento ${ }^{1}$; Pedro Luid de Sousa Oliveira ${ }^{2}$; Juliana Souza Milagres $^{3}$; Rafael Guimarães Silva Moraes ${ }^{2}$; Lino Roberto Ferreira ${ }^{4}$
\end{abstract}

DOI: https://doi.org/10.31692/2526-7701.IIICOINTERPDVAGRO.2018.00413

\section{Introdução}

O volume de aplicação pode ser caracterizado como o volume de calda aplicado por unidade de área, peso ou volume (MATUO, 1990), sendo que deve ser o mínimo possível de forma que proporcione o efeito biológico desejado (PALLADINI e SOUZA, 2005). Entretanto, não existe um volume fixo de calda a ser utilizado por hectare, o qual pode variar conforme o tipo de pulverizador, porte e estádio de desenvolvimento das plantas, espaçamento entre linhas, densidade de plantio, condições climáticas e o alvo biológico a ser controlado (PALLADINI e SOUZA, 2005).

O volume de calda não é o responsável pelo controle da praga, patógeno ou planta daninha, e sim a distribuição uniforme da calda no alvo desejado (VAN ZYL et al., 2014). Assim, a eficiência operacional é influenciada diretamente pelo volume de calda, visto que o tempo gasto para reabastecimento retarda o ritmo operacional dos pulverizadores (ANTUNIASSI e BOLLER, 2011), além da redução do volume diminuir o desperdício de água.

Diante do exposto, objetivou-se com este estudo avaliar a eficiência de diferentes volumes de pulverização na deposição de calda nos terços inferior, médio e superior de plantas de soja.

\footnotetext{
${ }^{1}$ Doutoranda em Fitotecnia, Universidade Federal de Viçosa - UFV, roxana.mendes@ hotmail.com;

${ }^{2}$ Estudante do curso de Eng. Agronômica, Universidade Estadual da Região Tocantina do Maranhão UEMASUL, pluid93@ hotmail.com;

${ }^{3}$ Estudante do curso de Eng. Agronômica, Universidade Federal de Viçosa - UFV;

${ }^{4}$ Professor do departamento de Fitotecnia, Universidade Federal de Viçosa - UFV.
} 


\section{Fundamentação Teórica}

Embora existam produtores que acreditam que altos volumes de calda sejam essenciais para que se obtenha sucesso na aplicação, ou seja, que boa eficiência depende de maior molhamento da superfície foliar das plantas ou o solo, isso nem sempre é verdade. O volume de calda não é o responsável pelo controle da praga, patógeno ou planta daninha, e sim a distribuição uniforme da calda no alvo desejado, uma vez que o molhamento excessivo ocasiona perdas por escorrimento (VAN ZYL et al., 2014).

Com o intuito de reduzir os custos de aplicação, tem sido verificada uma tendência em diminuir os volumes de calda de pulverização, desta forma, esta redução acarretará maior competitividade agrícola e sustentabilidade ambiental (TEIXEIRA et al., 2010). A eficiência operacional é influenciada diretamente pelo volume de calda, visto que o tempo gasto para reabastecimento retarda o ritmo operacional dos pulverizadores (ANTUNIASSI e BOLLER, 2011), além da redução do volume diminuir o desperdício de água. Isso requer aprimoramento da tecnologia de aplicação empregada, uma vez que para aplicação de menor volume é necessário o uso de gotas finas, com maior risco de perdas por deriva e evaporação, além de menor quantidade de calda depositada (BAYER et al., 2011).

\section{Metodologia}

O experimento foi conduzido na unidade experimental Diogo Alves de Melo da Universidade Federal de Viçosa - UFV, Viçosa, MG, a variedade de soja utilizada foi a IPRO RK 7214, ciclo de 115 a 120 dias, hábito de crescimento indeterminado, semeada no sistema de plantio direto, com espaçamento de $50 \mathrm{~cm}$ entrelinhas e estande final de 12 plantas por metro.

Utilizou-se o delineamento de blocos ao acaso, com quatro repetições, em esquema de parcelas subdivididas, sendo os volumes de pulverização as parcelas, e as sub parcelas os terços das plantas avaliados. Os tratamentos consistiram da avaliação de diferentes volumes de calda: $50 \mathrm{~L} \mathrm{ha}^{-1}$; $100 \mathrm{~L} \mathrm{ha}^{-1} ; 150 \mathrm{~L} \mathrm{ha}^{-1} ; 200 \mathrm{~L} \mathrm{ha}^{-1} ; 300 \mathrm{~L} \mathrm{ha}^{-1}$ e $400 \mathrm{~L} \mathrm{ha}^{-1}$. As aplicações foram realizadas com um pulverizador costal pressurizado a $\mathrm{CO}_{2}$, munido de uma barra com dois ou quatro bicos distanciados de 1,0 e 0,5m entre si, respectivamente, altura da barra de 0,5 m em relação à cultura, com ponta de aplicação do tipo jato plano, tipo leque, modelo TT 11001 da marca Teejet. A pressão de trabalho utilizada foi $500 \mathrm{KPa}$ (5 Bar) para todos os volumes, alterando, nesse caso, as velocidades de deslocamento para atingir os diferentes 
volumes. Foi realizada uma aplicação de fungicida no estádio fenológico R1.

As avaliações de depósito de calda nos terços superior, médio e inferior das plantas foram realizadas em todas as três aplicações, através de pulverizações com um traçador alimentício, o corante Azul Brilhante (catalogado internacionalmente pela empresa "Food, Drug \& Cosmetic" (FD\&C), como FD\&C Blue n.1), conforme metodologia de Palladini (2000), diluído em água na proporção de $3 \mathrm{~g} \mathrm{~L}^{-1}$. Após a aplicação, foram selecionadas 10 plantas por tratamento, de onde foram retirados três trifólios dos terços superior, médio e inferior, totalizando nove trifólios por planta, mantendo-os individualizados em sacos plásticos, posteriormente foram acondicionadas em caixas com isolamento térmico (isopor) e encaminhadas ao laboratório para extração do traçador. Para lavagem dos trifólios foram adicionados $20 \mathrm{~mL}$ de água destilada em cada saco plástico e submetidos a agitação, para a remoção do corante, e em seguida a solução da lavagem foi quantificada no espectrofotômetro de feixe duplo de UV- visível, para a leitura de absorbância no comprimento de onda de 630nm. Após a remoção do depósito, as folhas tiveram sua área foliar quantificada utilizando o medidor de área foliar de bancada. De posse da concentração inicial da solução com o corante e do volume de diluição das amostras, foi determinado o volume de corante retido nos trifólios.

Para obtenção do depósito na planta, foi feita a curva de calibração do espectrofotômetro, a partir de soluções com concentrações conhecidas do corante, que gerou uma equação de regressão. Os dados de absorbância foram transformados em volume $(\mu \mathrm{L})$, e em seguida feita a divisão do volume depositado pela área das folhas, obtendo-se, assim, a quantidade em $\mu \mathrm{L} \mathrm{cm}^{-2}$, através da expressão matemática:

$$
\text { Ci. Vi }=\text { Cf.Vf }
$$

em que:

$C i=$ concentração inicial na calda de aplicação (mg L-1);

$V i=$ volume retido pelo alvo $(\mathrm{mL}) ;$

$C f=$ concentração detectada em densidade óptica (mg L-1); e

$V f=$ volume de diluição da amostra de cada planta $(\mathrm{mL})$. 
O produto dessa expressão matemática foi dividido pela área foliar do respectivo trifólio e multiplicado por 1000 para transformação do volume retido pelo alvo de mL para $\mu \mathrm{L}$ (OLIVEIRA e MACHADO-NETO, 2003).

A partir dos dados obtidos de deposição foram realizados inicialmente o teste de normalidade e a homogeneidade de variâncias, em seguida foi aplicado o teste de análise de variâncias (teste F) e, posteriormente, o teste de comparação de médias (Tukey) a 5\% de probabilidade, e por fim uma análise de regressão.

\section{Resultados e Discussões}

Para a deposição de calda de pulverização houve interação significativa entre o volume de calda e os terços da planta de soja. Observa-se uma tendência de incremento dos níveis de depósito nos trifólios com o aumento do volume de calda nos três terços da planta de soja e nos três estádios fenológicos avaliados, conforme Figura 1. Portanto, os resultados demonstram a existência de uma relação diretamente proporcional entre o volume de calda e a deposição de calda nos trifólios de plantas de soja.

Figura 1: Valores médios, provenientes da análise conjunta, da deposição de calda $(\mu \mathrm{L})$ conforme os terços superior, médio e inferior, no estádio fenológico R1 de plantas de soja.

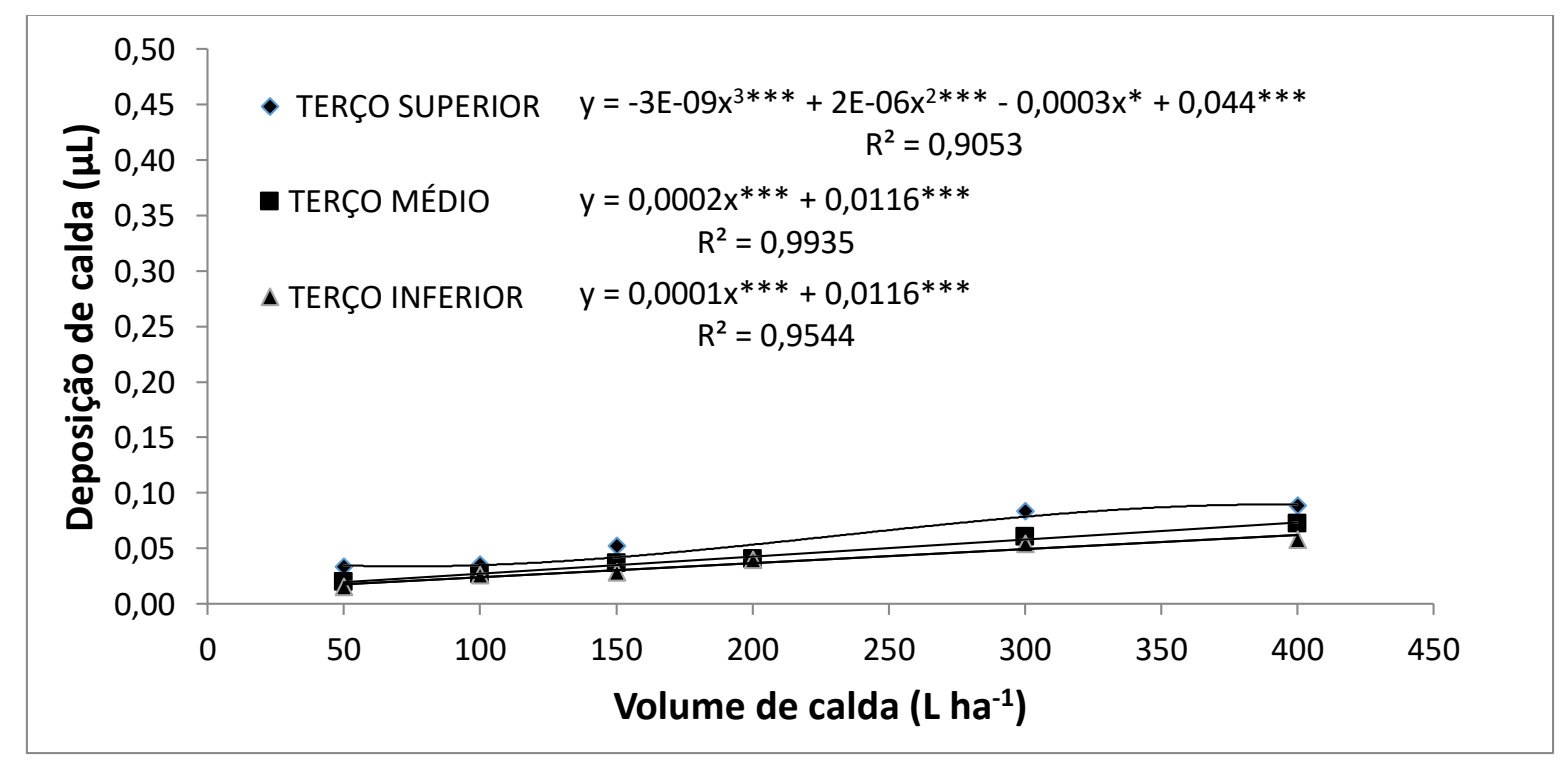

***Significativo a $0,001 \% ; * *$ Significativo a $1 \%$ e *Significativo a $5 \%$.

De acordo com os resultados obtidos, observou-se aumento na deposição de calda, nos três terços de plantas de soja, conforme o aumento do volume de calda de pulverização. 
Entretanto, nos três estádios fenológicos, houve maior deposição de calda para todos os volumes de calda no terço superior. Alguns estudos sobre depósito e cobertura da calda de pulverização demonstram a distribuição irregular do produto fitossanitário nos terços da planta, acarretando menor eficiência no controle do alvo biológico. Villalba et al. (2009) observaram depósitos em diferentes cultivares de soja, quase três vezes maior no terço superior quando comparado ao terço inferior.

No que se refere aos terços médio e inferior, para a deposição de calda, de forma geral, os terços médio e inferior não diferiram entre si para todos os volumes de calda avaliados, exceto para os volume de 300 e $400 \mathrm{~L} \mathrm{ha}^{-1}$. De acordo com Cunha et al. (2011), o maior depósito da pulverização fica retido nos trifólios da parte superior das plantas e a deposição nos trifólios mais internos do dossel não apresenta a mesma proporção do incremento. Os menores depósitos de calda na parte inferior da planta, quando comparada à parte superior, podem ser explicados em função da arquitetura foliar e índice de área foliar, e desta forma, podem variar conforme a cultivar de soja.

Uma medida que pode ser tomada para aumentar a deposição de calda, caso seja necessário é a aplicação de fungicida com os volumes reduzidos em estádio fenológico anterior ao R1, por exemplo, em estádio V6, onde as plantas estarão com índice de área foliar mais reduzido. A penetração do ingrediente ativo no interior do dossel é condição essencial para o controle eficaz, à medida que a cultura cresce, atingir as camadas inferiores do dossel se torna cada vez mais difícil.

\section{Conclusões}

Existe uma relação direta entre o aumento do volume de calda e os níveis de depósito, nos terços superior, médio e inferior de plantas de soja. Além disso, a maior deposição de calda ocorre no terço superior, em relação aos terços médio e inferior.

\section{Referências}

ANTUNIASSI, U. R.; BOLLER, W. Tecnologia de aplicação de fungicidas. In: ANTUNIASSI, U.R.; BOLLER, W. Tecnologia de aplicação para culturas anuais. Passo Fundo: Aldeia Norte; Botucatu: FEPAF, 2011. p. 221-229.

BAYER, T.; COSTA, I. F. D.; LENZ, G.; ZEMOLIN, C.; MARQUES, L. N.; STEFANELO, M. S. Equipamentos de pulverização aérea e taxas de aplicação de fungicida na cultura do arroz irrigado. Revista Brasileira de Engenharia Agrícola e Ambiental, Campina Grande, v. 15, n. 2, p. 192-198, 2011. 
CUNHA, J. P. A. R.; FARNESE, A. C.; OLIVET, J. J.; VILLALBA, J. Deposição de calda pulverizada na cultura da soja promovida pela aplicação aérea e terrestre. Engenharia Agrícola, Jaboticabal, v. 31, n. 2, p. 343-351, 2011.

MATUO, T. Técnicas de aplicação de defensivos agrícolas. Jaboticabal: FUNEP, 1990. 139 p.

OLIVEIRA, M. L.; MACHADO-NETO, J. G. Use of tracer in the determination of respiratory exposure and relative importance of exposure routes in safety of pesticide applicators in citrus orchards. Bulletin of Environmental Contamination and Toxicology, Flórida, v. 70, n. 3, p. 415-21, 2003.

PALLADINI, L. A. Metodologia para avaliação da deposição em pulverizações. 2000. 111 p. Tese (Doutorado em Proteção de Plantas) - Faculdade de Ciências Agronômicas, Universidade Estadual Paulista "Júlio Mesquita Filho", Botucatu, 2000.

TEIXEIRA, E. S.; OSIPE, J. P.; GANDOLFO, U. D.; OLIVEIRA, J. F.; GANDOLFO, M. A.; OSIPE, ROBINSON. Uso de baixo volume oleoso e assistência de ar no controle de plantas daninhas. Semina: Ciências Agrárias, Londrina, v.31, supl. 1, p. 1229-1234, 2010.

VAN ZYL, J. G.; SIEVERDING, E. G.; VILJOEN, D. J.; FOURIE, P. H. Evaluation of two organosilicone adjuvants at reduced foliar spray volumes in South African citrus orchards of different canopy densities. Crop Protection, Amsterdam, v.64, p.198-206, 2014.

VILLALBA, J. F.; DAGOBERTO, M.; COSTA, N. V.; DOMINGOS, V. D. Deposição da calda de pulverização em cultivares de soja no estádio R1. Ciência Rural, Santa Maria, v. 39, n. 6, p. 1738-1744, 2009. 